\title{
EXTENSION OF ATMOSPHERIC CORRECTION POLYMER TO HYPERSPECTRAL SENSORS: APPLICATION TO HICO AND FIRST RESULTS FOR DESIS DATA
}

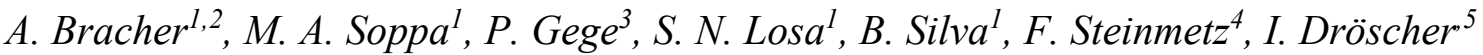 \\ ${ }^{1}$ Alfred Wegener Institute Helmholtz Centre for Polar and Marine Research, Bremerhaven, Germany \\ ${ }^{2}$ Institute of Environmental Physics, University of Bremen, Bremen, Germany \\ ${ }^{3}$ German Aerospace Center (DLR), Remote Sensing Technology Institute, Oberpfaffenhofen, Germany \\ ${ }^{4}$ HYGEOS, Euratechnologies, Lille, France \\ ${ }^{5}$ Institut für Seenforschung der Landesanstalt für Umwelt Baden-Württemberg (ISF-LUBW), Langenargen, Germany
}

\begin{abstract}
Satellite sensor configurations enabling high spatial and high spectral resolution could be far more suited for monitoring inland and coastal water ecosystems' water quality than common ocean color sensors. It is expected that even the composition of phytoplankton, the primary producer in these ecosystems, could be determined. Up to now, atmospheric correction is limiting the exploitation of these sensors' data. Here, we evaluate the atmospheric correction method Polymer applied to hyper- and multispectral satellite data (HICO, DESIS and OLCI) over coastal and inland waters. We assess the quality of retrieved water reflectance and biomass for all and specific phytoplankton groups by comparison to in-situ matchup data and results from other retrieval methods.
\end{abstract}

Index Terms - phytoplankton groups, water reflectance, atmospheric correction, HICO, DESIS

\section{MOTIVATION AND OBJECTIVES}

About $40 \%$ of the world's population lives in a $100 \mathrm{~km}$ distance to coastlines and $90 \%$ in a $10 \mathrm{~km}$ distance to freshwater bodies. This population depends on those aquatic ecosystems that are spatially diverse, temporally dynamic and continuously impacted by natural processes and human activities. Hence, there is a need to generate reliable, robust and timely records of how these environments are changing. Hyperspectral remote sensing has a tremendous perspective to improve and extend the current water color products, especially in terms of phytoplankton composition, a proxy for assessing environmental changes. Improvements should arise from satellite sensor configurations enabling high spatial and spectral resolution monitoring of inland and coastal water ecosystems. The first hyperspectral ocean color sensor HICO (Hyperspectral Imager for the Coastal Ocean) operated from 2009 to 2014 on the ISS. The potential of hyperspectral technology for water color research was confirmed, but the sensor exhibited issues with radiometric and spectral calibra-
HICO - Venice Bay - 25.09.2010
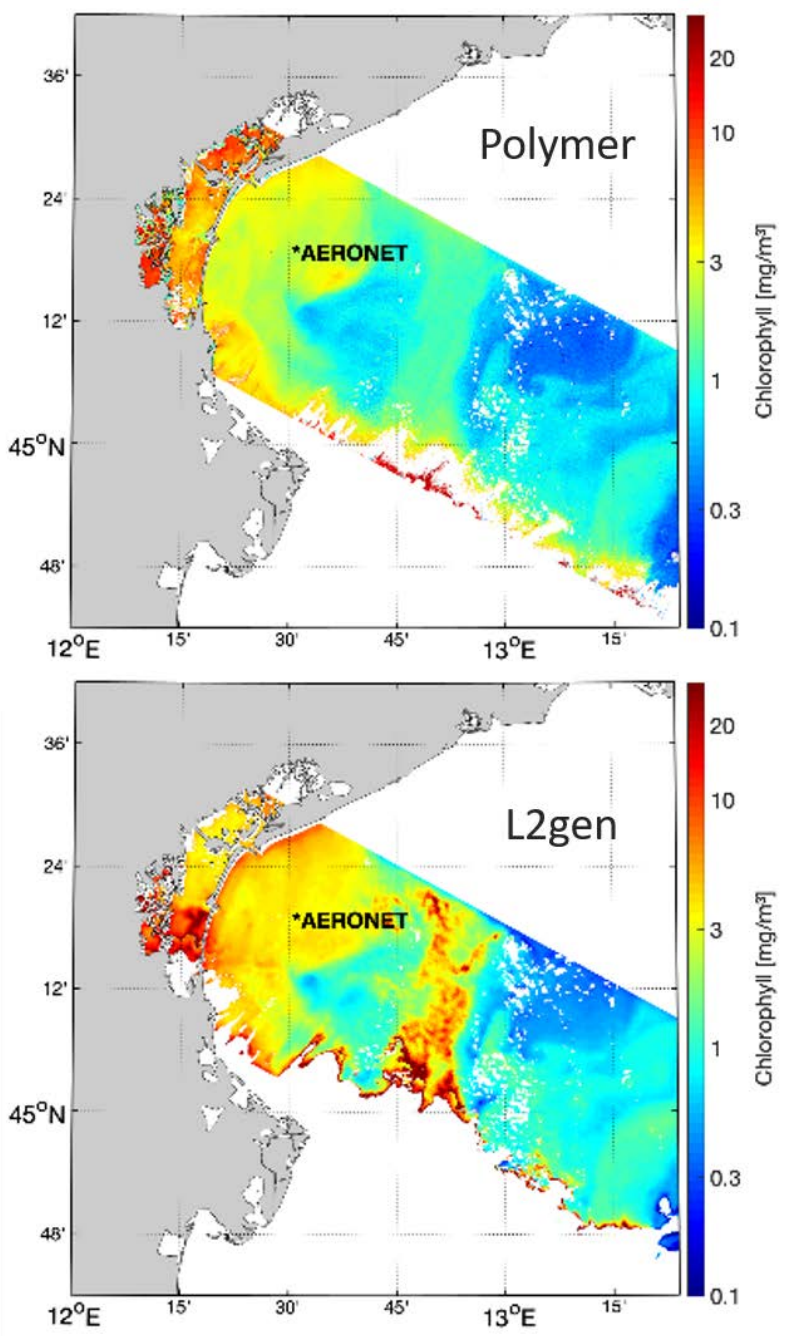

Figure 1: HICO-Chla image from 25 Sep 2010 around Venice Bay area in the northern Adriatic Sea after applying Polymer (top) and 12gen (bottom) atmospheric corrections. 
tion, and geolocation accuracy that, together with the lack of more dedicated studies on atmospheric correction (AC), prevented to explore HICO spectral data: Not much more than standard chlorophyll-a concentration (Chla) was derived (e.g., Braga et al. 2013), except that the appearance of a red tide bloom was verified (Dierssen et al. 2015). Ibrahim et al. (2018) extended the NASA 12gen algorithm to improve the $\mathrm{AC}$ for $\mathrm{HICO}$ and recently the retrieval of hyperspectral phytoplankton absorption from $\mathrm{HICO}$ water remote sensing reflectance $\left(\mathrm{R}_{\mathrm{RS}}\right)$ data has been shown (Pahlevan et al. 2021). Further, the AC method Polymer (Steinmetz et al. 2011, Steinmetz et al. 2016) was extended for processing of HICO hyperspectral satellite data (Soppa et al. 2019).
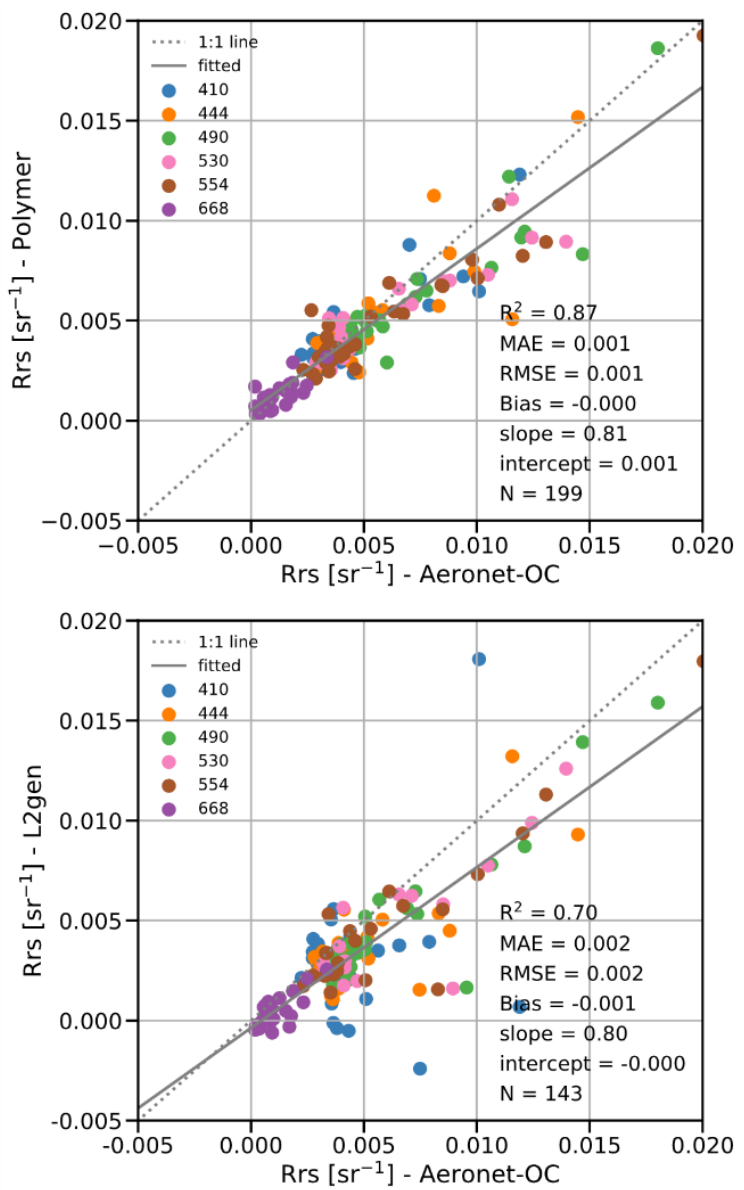

Figure 2: Scatter plots of Rrs retrieved by Polymer (top) and L2gen (bottom) versus in situ AERONET-Rrs at Acqua Alta (see Fig. 1). Matchups criteria following Brewin et al. (2015).

In this work, we apply the Polymer AC to process hyperspectral satellite data of HICO and, for the first time, DESIS (DLR's Earth Sensing Imaging Spectrometer) obtained over coastal and inland waters. We assess the quality of retrieved $R_{R S}$, and Chla for all and specific phytoplankton groups by comparison to in-situ matchup data and results from other AC methods (12gen) and sensors (Sentinel-3).

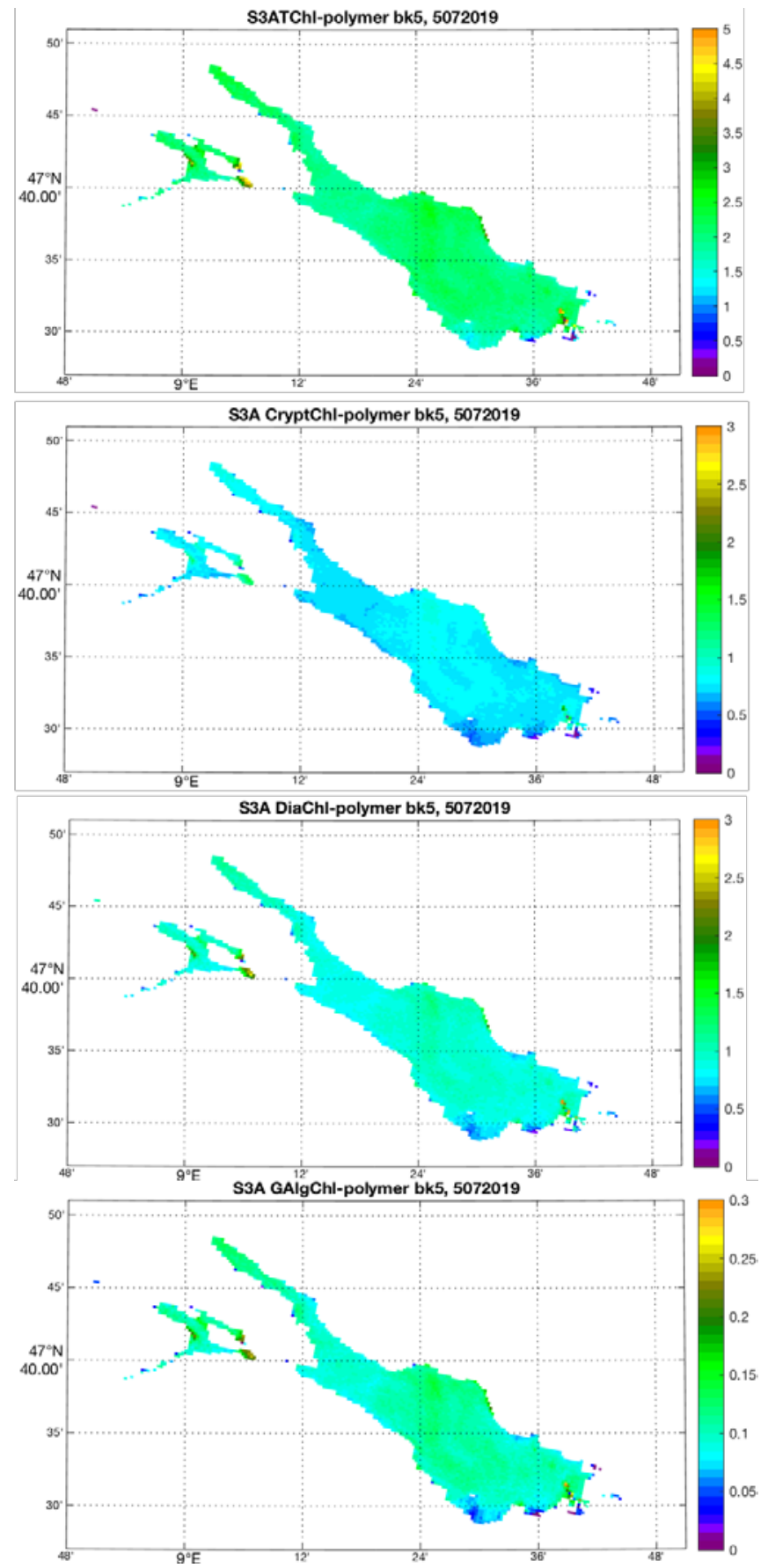

Figure 3 (from top to bottom): Total Chla (TChla) and Chla for cryptophytes, diatoms, and green algae derived with the Lake Constance OC-PFT algorithm from $\mathrm{R}_{\mathrm{RS}}$ data (retrieved from top of atmosphere $\mathrm{S} 3$ radiances after Polymer AC).

\section{METHODS, RESULTS AND CONCLUSIONS}

All HICO L1 data covering the Venice Bay area (2010-2014, $\sim 65$ images) were processed using Polymer AC (more details in Soppa et al. 2021). For comparison, HICO L2 data processed with 12gen (SeaDAS v.7.5.1, 2018) were obtained 
from the NASA website (https://oceancolor.gsfc.nasa.gov/). HICO-Chla derived from both AC methods shows similar spatial variability and magnitude (Fig. 1), but with Polymer, cloud adjacency effects were better corrected or flagged, and more pixels were retrieved than with 12 gen. For $R_{R S}$ from both AC methods vs. in situ from AERosol Robotic NETwork - Ocean Colour (AERONET-OC) Aqua Alta Tower shows much better statistical results and about $25 \%$ more valid matchups for HICO-Polymer as compared to HICO-12gen (Fig. 2).

Additionally, we assessed the performance of Polymer AC over inland water at Lake Constance. Firstly, Polymer was applied to the multi-spectral Sentinel-3 OLCI (S3) data which was then processed to retrieve total Chla and phytoplankton group specific Chla (Fig. 3). For the latter, the OC-PFT method (Hirata et al. 2011, Losa et al. 2017) was updated to Lake Constance phytoplankton pigment relationships obtained from the long-term ISF-LUBW/IGKB HPLC Lake Constance data set. DESIS L1 data, only 1 day off from the S3 data, was atmospherically corrected by Polymer and the operational DESIS method ATCOR (Alonso et al. 2019). The resulting DESIS $R_{R S}$ data were used by the WASI-2D inversion method (Gege 2004, Gege 2014) to retrieve bulk water constituents and phytoplankton groups (Figure 4). Here, WASI-2D was calibrated with specific inherent optical properties measured at Lake Constance in March 2020. DESIS-WASI results show that the dominance and range of Chla of green algae was well retrieved as compared to S3 OCPFT data, but not for diatoms which shows very low concentrations. The much lower radiometric resolution of DESIS compared to S3 certainly increases the threshold concentration of phytoplankton. More adaptations for using DESIS data within WASI-2D, especially correcting the sensor's specific deficiency in calibration between 400 to 450 $\mathrm{nm}$, seem to be necessary to retrieve more realistic phytoplankton classifications. One has to bear in mind that also the abundance based method OC-PFT is limitied in its application since it cannot predict atypical associations (Bracher et al. 2017). Processing more matchup data of S3 and DESIS including thorough validation with in situ group specific Chla can help to determine uncertainties and further improve both phytoplankton group retrievals.

\section{ACKNOWLEDGMENTS}

This study was funded by the Federal Ministry of Economics and Technology (BMWi) and DLR grants number $50 \mathrm{EE}$ 1620, 50EE1915 and 50 EE 1923 and grant "SeeWandel: Life in Lake Constance-the past, present and future" within the framework of the Interreg $\mathrm{V}$ programme "AlpenrheinBodensee-Hochrhein (Germany/Austria/Switzerland/Liechtenstein)" which funds are provided by the European Regional Development Fund as well as the Swiss Confederation and cantons. The funders had no role in study

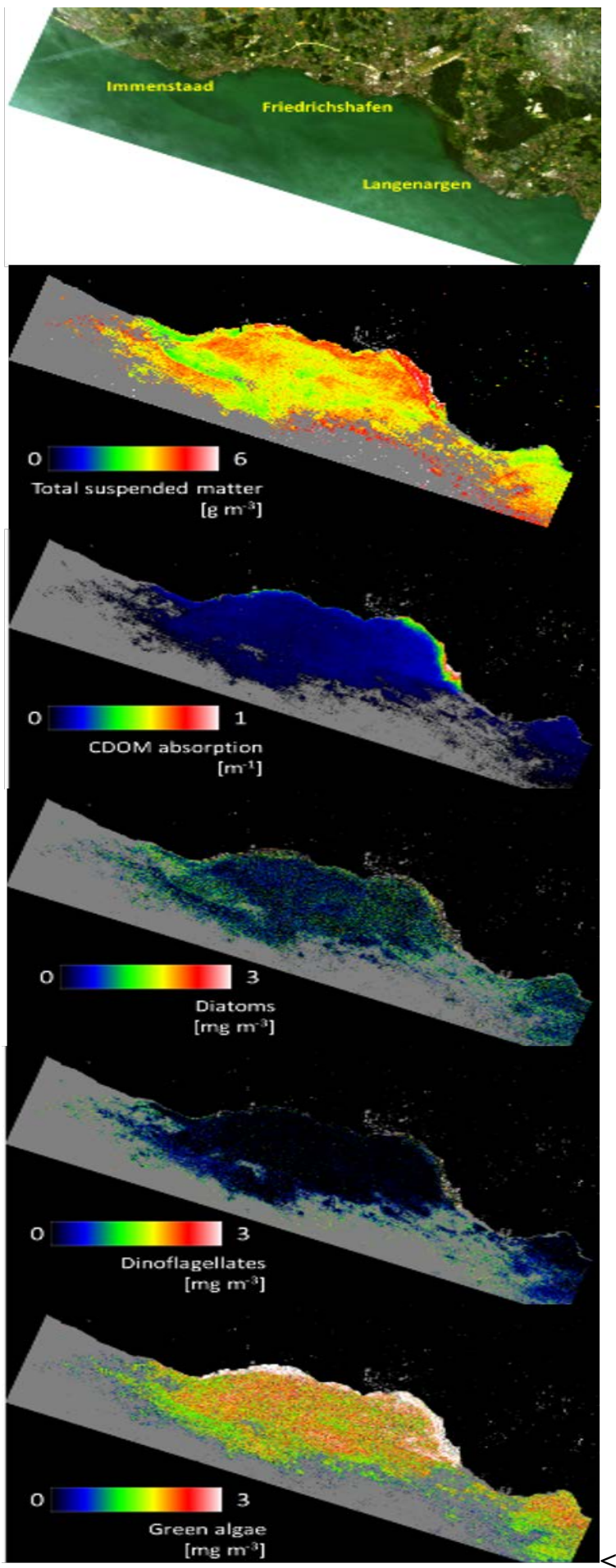

Figure 4: DESIS Level-2A 6 July 2019 (DESIS-HSI-L2ADT0337571168_003-20190706T061015-V0207-QL_IMA.) RGB (top panel) from bands 16, 18, 21 (440 nm, 550nm, $630 \mathrm{~nm}$ ) covering a part of Lake Constance and processed with WASI-2 excluding clouded areas: total suspended matter concentration $\left[\mathrm{g} \mathrm{m}^{-1}\right]$, colored dissolved organic matter absorption (CDOM, $\left[\mathrm{m}^{-1}\right]$ ) and phytoplankton classification, given as group specific Chla $\left[\mathrm{mg} \mathrm{m}^{-1}\right]$. 
design, data collection and analysis, decision to publish, or preparation of the manuscript. We thank G. Zibordhi (JRC) as the principal investigator responsible for AERONET-OC Acqua Alta, the International Commission of Lake Constance Water Conservation ("Internationale Gewässerschutzkommission für den Bodensee, IGKB"), Julia Oelker (U. Bremen/AWI) for supporting optical sampling at Lake Constance in March 2020, the ISF-LUBW for collecting and providing HPLC data, NASA for HICO, DLR and Teledyne for DESIS, EUMETSAT and ESA for S3 data.

\section{REFERENCES}

1. Alonso K., et al. (2019) Data products, quality and validation of the DLR Earth Sensing Imaging Spectrometer (DESIS). Sensors 19, 4471.

2. Bracher A., et al. (2017) Obtaining Phytoplankton Diversity from Ocean Color: A Scientific Roadmap for Future Development. Frontiers in Marine Science 4: 00055.

3. Braga F., et al. (2013) Assessing water quality in the northern adriatic sea from HICO data. Remote Sens. Lett. 4, 1028-1037.

4. Brewin RJW, et al. (2015) The Ocean Colour Climate Change Initiative: III. A round-robin comparison on in-water bio-optical algorithms. Remote Sensing of Environment 162:271-294. https://doi.org/10.1016/j.rse.2013.09.016

5. Dierssen H., et al. (2015) Space station image captures a red tide ciliate bloom at high spectral and spatial resolution. PNAS 112 (48) 14783-14787;

6. Gege P. (2004). The water colour simulator WASI: An integrating software tool for analysis and simulation of optical in-situ spectra. Computers and Geosciences 30, 523-532.

7. Gege P. and A. Albert (2006). A tool for inverse modeling of spectral measurements in deep and shallow waters. In: L.L. Richardson and E.F. LeDrew (Eds): "Remote Sensing of Aquatic Coastal Ecosystem Processes: Science and Management Applications", Kluwer book series: Remote Sensing and Digital Image Processing, Springer, ISBN 14020-3967-0, pp. 81-109.

8. Gege P. (2014) WASI-2D: A software tool for regionally optimized analysis of imaging spectrometer data from deep and shallow waters. Computers \& Geosciences 62, 208-215

9. Hirata $T$., et al (2011) Synoptic relationships between surface Chlorophyll- $a$ and diagnostic pigments specific to phytoplankton functional types. Biogeosciences, 8: 311-327, doi:10.5194/bg-8-3112011.

10. Ibrahim A., et al. (2018) Atmospheric correction for hyperspectral ocean color retrieval with application to the Hyperspectral Imager for the Coastal Ocean (HICO). Rem. Sens. Env. 204, 60 - 75.
11. Pahlevan N., et al. (2021) Hyperspectral retrievals of phytoplankton absorption and chlorophyll-a in inland and nearshore coastal waters. Remote Sensing of Environment, 2021, 253, 112200

12. Soppa M.A., Silva B. G., Steinmetz F., Bracher A. (2019) Evaluation of Polymer atmospheric correction algorithm applied to HICO images over coastal waters. Poster at at International Ocean Colour Science (IOCS), Busan, Korea, 9-12 Apr 2019

13. Soppa M. A., Silva B., Steinmetz F., Keith D., Scheffler D., Bohn N., Bracher A. (2021) Assessment of Polymer atmospheric correction algorithm for hyperspectral remote sensing imagery over coastal waters; Sensors; Special Issue Remote Sensing of Water Quality and Water Environment sensors-1217422; in press

14. Steinmetz F., et al. (2011) Atmospheric correction in presence of sun glint: application to MERIS. Optics Express 19, 9783-9800.

15. Steinmetz F., et al. (2016) ATBD v1 - Polymer atmospheric correction algorithm, D2.3 145 OCCCI project. Technical report. 